\title{
资源环境承载能力预警的超载成因分析方法及应用
}

\author{
徐 勇 ${ }^{1}$, 张雪飞 ${ }^{1,2}$, 周 㑆 ${ }^{1}$, 王传胜 ${ }^{1}$, 徐小任 ${ }^{1,2}$
}

(1. 中国科学院地理科学与资源研究所, 北京 100101；2. 中国科学院大学, 北京 100049)

\begin{abstract}
摘 要: 建立资源环境承载能力监测预警机制和对超载区域实行限制性措施是中央全面深化改革的一项重大任务, 而超载成因分析既是资源环境承载能力监测预警技术方法的重要组成内容, 也是制定超载区域限制性政策的基 础。本文在搭建超载成因分析总体框架、阐述关键因素识别和成因分析方法的基础上,梳理总结了陆域海域基础 和专项评价结果以及综合预警超载成因分析的要点, 进而在京津冀地区进行了实证应用。研究结果表明, 导致京 津冀地区资源环境超载的因素涉及自然、发展和管理各个类别, 但关键因素的作用程度及其组合叠加状况在基础 评价结果、专项评价结果和综合预警超载成因方面存在较大差异; 水资源严重短缺、地形和气象等自然条件是导致 超载的基础原因; 人口和产业过度集聚以及低端产业、能源消费结构等发展类因素是超载的首要原因; 内海净化能 力差和海域生态退化、海岸开发强度大综合导致了海域生态环境超载; 现行的资源环境管理政策尚不具备有效遏 制和解决资源环境超载的能力。既有的超载成因分析框架、方法及要点可供各省、市、自治区开展资源环境承载能 力监测预警借鉴。
\end{abstract}

关 键 词: 资源环境承载力; 超载成因; 因素叠加分析法; 京津冀地区

\section{1 引言}

建立资源环境承载能力监测预警机制,对水土 资源、环境容量和海洋资源超载区域实行限制性措 施, 是中央全面深化改革的一项重大任务 (Xu et al, 2011; 王传胜等, 2012; 柇杰等, 2015)。2014年1月, 中共中央审议通过并印发了《中央有关部门贯彻落 实党的十八届三中全会<决定>重要举措分工方 案》, 按照党中央、国务院部的署要求, 国家发展和 改革委员会会同中国科学院及国家相关部委共同 承担 “建立资源环境承载能力监测预警机制” 深化 改革任务(中办 [2014]8 号)。3 年来, 通过借鉴全国 主体功能区规划工作的成功经验(徐勇等, 2009; Fan et al, 2012; 㚞杰, 2015), 结合京津冀地区资源环 境承载能力监测预警试点工作, 形成了《资源环境 承载能力监测预警技术方法(试行)》。该技术方法 由总则、陆域评价、海域评价、集成评价、成因解析
和政策预研等部分构成(发改规划[2016]2043 号)， 重点阐释了资源环境承载能力的概念和监测预警 宜遵循的基本原则，搭建了监测预警总体技术流 程; 按照陆域水土资源、环境、生态基础要素以及城 市化地区、农业地区、重点生态功能区选建了由 8 个 综合指标、19个分项指标和 56 个以上属性指标构 成的陆域监测预警指标体系,按照海域海洋空间资 源、渔业资源、生态环境、海岛资源环境基础要素以 及重点开发用海区、海洋渔业保障区、重要海洋生 态功能区选建了由 7 个综合指标、 12 个分项指标和 30 个以上属性指标构成的海域监测预警指标体系; 较为系统地介绍了综合指标算法、陆域和海域基础 评价、专项评价、过程评价、集成评价以及超载类 型、预警等级划分等方法, 概括了超载成因分析和 限制性政策预研的要点内容。显然,超载成因分析 既是限制性政策预研的基础, 又是监测预警技术方 法的组成部分。从已有的文献和研究成果看(党丽

收稿日期: 2017-02; 修订日期: 2017-03。

基金项目: 国家自然科学基金项目(41630644); 中国科学院科技服务网络计划(STS 计划)项目(KFJ-STS-ZDTP-021) [Foundation: National Natural Science Foundation of China, No. 41630644; Science and Technology Service Network Initiative of the Chinese Academy of Sciences, No. KFJ-STS-ZDTP-021]。

作者简介: 徐勇(1964-), 男, 博士, 研究员, 博士生导师, 主要从事土地利用与人地关系机理模拟、农业与乡村发展、资源环境承 载能力评价等方面的研究,E-mail: xuy@igsnrr.ac.cn。

引用格式: 徐勇, 张雪飞, 周㑆, 等. 2017. 资源环境承载能力预警的超载成因分析方法及应用[J]. 地理科学进展, 36(3): 277-285. [Xu Y, Zhang X F, Zhou K, et al. 2017. Method and application of cause analysis for early-warning of resource and environmental system overloading [J]. Progress in Geography, 36(3): 277-285.]. DOI: 10.18306/dlkxjz.2017.03.002 
娟等, 2015; 汤青等, 2015; 徐勇等, 2016; 周㑆等, 2016), 目前与资源环境承载能力预警超载成因分 析相关的研究多局限于单项评价要素, 即以单要素 为目标通过探究影响因素与超载或压力特征值之 间的关系进行成因解析, 而专门针对多要素和多层 级评价目标的预警超载成因分析尚存在方法体系 缺失和影响因素层序不清等问题。为此, 本文试图 在搭建超载成因分析总体框架、阐释关键因素识别 和成因分析基本方法的基础上,概括陆域/海域基础 和专项评价结果以及综合预警等级类区成因分析 的要点, 并通过对京津冀地区的应用案例剖析, 希 望能为目前正在开展的各省、市、自治区资源环境 承载能力监测预警提供一些有益的帮助。

\section{2 分析方法}

\section{1 总体框架}

资源环境承载能力的研究历程是伴随资源环 境问题而发展的, 且关注的要素逐渐从单项走向综 合。 20 世纪 70 年代自然资源耗竭问题成为承载能 力研究的转折点(Ehrlich et al, 1971; House, 1974), 80-90 年代研究重点转移至可再生资源的探索, 2000 年前后环境污染问题凸显, 承载能力的研究又 从资源耗竭拓展到了环境容量层面(Price, 1999)。 历史地看, 尽管已有研究成果未对超载成因开展过 专题性分析, 但从其研究思路、内容、方法模型涉及 的因素变量以及提出的对策建议看, 导致资源环境 超载是自然本底条件有限、人类活动强度过大和管 理政策体系不完善等共同作用的结果。因此, 超载
成因分析远较资源环境承载能力监测预警本身更 为宽泛和复杂, 涉及的因素、内容需从更广泛视角、 更大时间跨度和地域空间尺度加以界定。资源环 境承载能力监测预警按照基础评价、专项评价和综 合集成评价的技术流程,超载成因分析至少应包括 关键因素识别、成因分析方法以及针对陆域/海域基 础评价结果、专项评价结果、陆海综合预警等级类 区成因分析等环节和内容(图 1)。

\section{2 关键因素识别}

影响因素识别是进行超载成因分析的先决条 件。超载成因分析需先依据基础、专项、预警等涉 及要素及指标选择情况, 结合地域特点识别出导致 超载的影响因素。一般而言,影响资源环境承载能 力的因素可概括为自然、发展和管理等 3 类(表 1$)$ 。 自然类因素包括水土资源条件和生态及环境本底 状况; 发展类因素是指人类活动状况, 包括经济社 会发展方式、规模、结构、速度等;管理类因素包括 管理方式、政策法规、体制机制、技术标准等。其 次,针对基础、专项和预警评价结果,篎选导致超载 的关键类因素及其隶属因子,为超载成因分析提供 有限的因素及因子范围和明确的目标导向。第三, 理清关键因素及其隶属因子与超载状态之间可能 存在的作用关系, 为选择不同的超载成因分析方法 提供参考依据。

\section{3 成因分析基本方法}

资源环境超载成因分析有多种方法, 按因素类 型三分法进行组合(图 2), 一般可以划分为 3 种方 法:即单因素类分析法、双因素类组合分析法、多因 素类叠加分析法。单因素类分析法是指资源环境

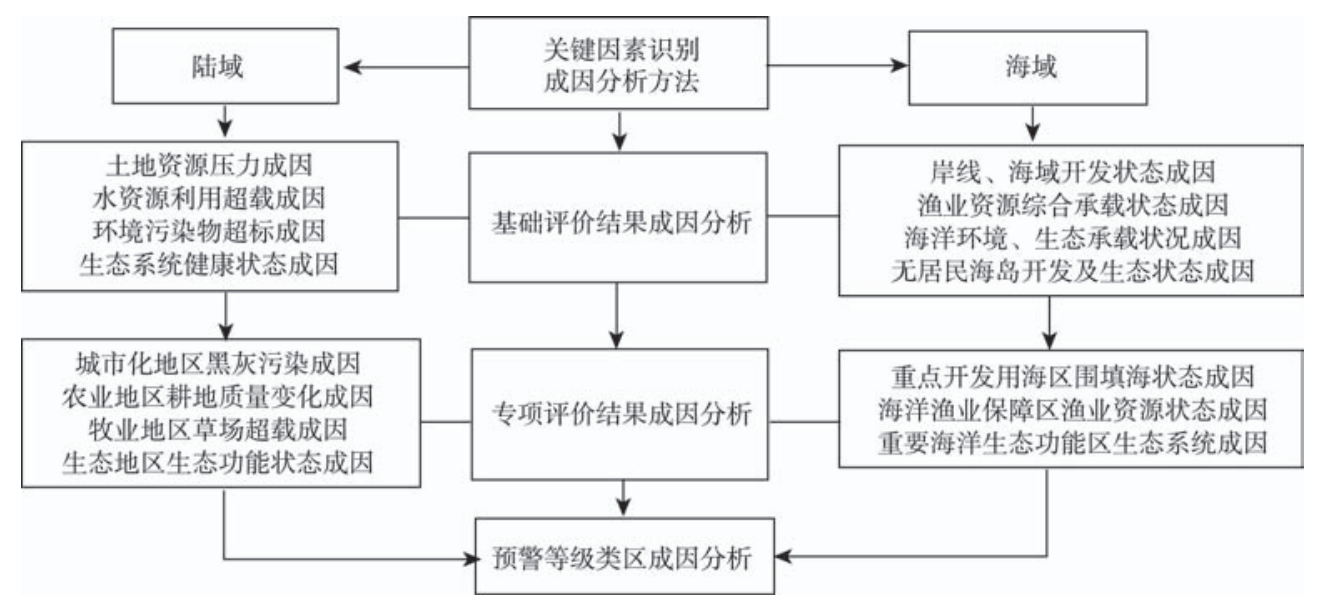

图 1 资源环境超载成因分析总体框架

Fig.1 Framework for cause analysis of resource and environmental system overloading 
表 1 资源环境超载成因影响因素及隶属因子

Tab.1 Influencing factors and indicators for the overloading of resource and environmental system

\begin{tabular}{|c|c|c|}
\hline \multicolumn{2}{|c|}{ 因素类型 } & \multirow{2}{*}{$\begin{array}{c}\text { 因素及隶属因子 } \\
\text { 地形地貌、可利用土地、土地利用现状、开发强度等 }\end{array}$} \\
\hline 自然类 & 土地资源 & \\
\hline & 水资源 & 降水、地表水、地下水、可利用水资源量、水资源利用量等 \\
\hline & 环境 & 大气环境容量、水环境容量、土壤环境容量、废气排放、废水排放、固废排放等 \\
\hline & 生态 & 水土流失、土地沙漠化、土地石漠化、土壤盐渍化、植被覆盖等 \\
\hline & 其他 & 地质条件、气象条件、地质灾害、气象灾害等 \\
\hline \multirow[t]{3}{*}{ 发展类 } & 人口 & 人口数量、人口集聚程度、就业结构、人口城镇化等 \\
\hline & 产业 & 产业类别、产业规模、产业结构、产业集聚程度、产业发展阶段等 \\
\hline & 其他 & 经济发展方式、速度、区际联系、能源消费构成、居民生活方式等 \\
\hline \multirow[t]{4}{*}{ 管理类 } & 管理方式 & 目标设定、组织体系、职责及权限、方法及程序等 \\
\hline & 法规 & 与资源环境相关的法律、行政法规、部门条例、地方性法规等 \\
\hline & 政策 & 财政、投资、产业、土地、人口管理、环境保护以及绩效评价和政绩考核等政策 \\
\hline & 其他 & 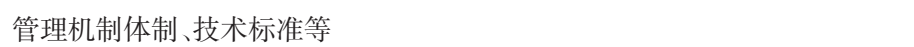 \\
\hline
\end{tabular}

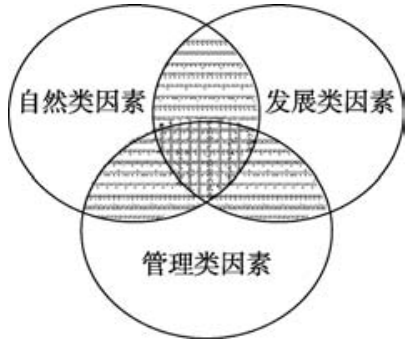

图 2 资源环境超载影响因素组合一叠加示意图

Fig.2 Interaction of influencing factors of resource and environmental system overloading

超载的成因只涉及一类因素, 主要通过此类影响因 素所涉及一种或几种因素的分析,阐释超载原因， 包括自然因素类分析法、发展因素类分析法和管理 因素类分析法(图 2 的空白区域超载成因分析采用 此方法)。双因素类组合分析法是指资源环境超载 的成因涉及两类因素, 每类因素中至少有一种因素 是超载的原因, 通过相关因素分析, 进行原因解析, 包括自然因素+发展因素类分析法、发展因素+管理 因素类分析法和自然因素+管理因素类分析法(图 2 的横线区域超载成因分析采用此方法)。多因素类 叠加分析法主要针对超载成因涉及 3 类因素的区域 (图 2 中方格区域), 成因分析采用多因素类叠加分 析法,即自然因素+发展因素+管理因素类分析法。 运用以上 3 种成因分析方法, 并结合因子分析、层次 分析、主成分分析以及其他定量分析等方法, 可对 基础评价结果、专项评价结果和预警等级类区的超 载状况进行成因分析。需要特别说明的是, 在对特 定区域资源环境超载成因分析时, 上述 3 种方法也 适用于来源于同一类型的不同因素, 采用的分析方
法即为单因素分析法、双因素组合分析法、多因素 叠加分析法。

\section{4 基础评价结果成因分析}

针对土地资源、水资源、环境和生态四要素评 价结果,从自然本底条件、经济社会发展和管理政 策体系三个维度进行成因分析。依据土地资源禀 赋的区域差异(吴传钧等, 1994), 阐释区域建设开发 适宜性的限制因素; 结合区域经济社会发展特点， 分析超载区 “生产一生活一生态”空间用地数量和 质量变化, 阐释国土开发强度差异导致的土地资源 压力变化;分析区域发展政策导致的用地需求变化 以及对区域土地资源的影响。依据水资源超载地 区地表水和地下水的时空分布特征、水质状况及用 水结构,识别分析导致水资源超载的关键因素; 通 过与国际、国内生产生活用水指标及不同行业用水 效率对比,分析区域水资源开发利用水平, 阐释用 水结构对水资源超载的影响程度; 从水资源开发、 利用分配以及水权转让和水市场交易等方面, 分析 水资源管理体制机制存在的问题,解析其对水资源 供需状况的影响。针对环境污染物浓度综合超标 评价结果, 解析区域大气环境和水环境主要污染物 的构成及排放源特征; 分析主要污染物排放与区域 经济增长、产业结构、能矿资源开发、城镇化发展之 间的关系，阐释不同发展方式导致的污染物浓度超 标原因; 从环保法规配套性、政策有效性、监督机构 健全度以及环境污染处罚、赔偿等方面分析政策法 规与监管执法中存在的问题。依据生态系统的类 型、结构和功能等本底条件, 分析区域生态系统的 脆弱性和抗干扰能力; 分析经济社会发展及水、土、 
能矿等资源开发对区域生态系统的影响, 尤其是过 伐、过牧、过垦等人类活动对森林、草地和湿地生态 系统的破坏性影响; 分析自然保护区划定、天然林 保护、退耕还林还草等生态保护政策对改善区域生 态安全的作用和存在的不足。

海域基础评价结果成因分析的思路基本与陆 域相同,两者的区别仅在于评价要素的差异。海域 基础评价结果成因分析的要点在于从海域自然本 底条件、涉海人类活动以及管理政策体系 3 个方面, 解析岸线和海域开发状态、渔业资源综合承载状 态、海洋环境和生态承载状况、无居民海岛开发及 生态状态等的成因。

\section{5 专项评价结果成因分析}

针对城市化、农业、牧业和生态四类功能区专 项评价结果, 从自然本底条件、经济社会发展和管 理政策体系三个维度进行成因分析。城市化地区 重点分析气象条件不同形成的 PM2.5 超标天数和 由于径流条件不同形成的黑臭水污染级别的城市 间差异; 解析资源开发利用方式和生产工艺水平对 城市化地区环境质量的影响, 分析生活能源构成和 交通污染物排放对 PM2.5 的贡献, 分析城市功能区 布局对黑臭水分布的影响; 分析 PM2.5、黑臭水防 控措施等对改善污染状况的作用和存在的问题。 农业地区重点依据光、温、水、土等自然本底条件及 组合匹配特点, 分析不同种植制度和结构等对耕地 质量变化的影响; 解析化肥、农药、地膜使用以及秸 秆还田、增施有机肥等措施对耕地肥力变化的影响 程度; 分析耕地产权制度、耕地占补平衡等政策因 素所引起的耕地质量变化情况。牧业地区重点分 析影响草场质量及其变化的气候条件、水土资源及 牧草组分等因素; 分析放牧方式、放牧强度等对草 场质量变化的影响; 分析草场产权制度、草畜平衡、 干部绩效考核等政策因素的影响。生态地区重点 分析生态系统组成、功能结构等对生态安全格局及 变化的影响; 分析过牧过层过伐等人类活动对生态 系统的影响; 分析生态补偿、生态保护工程、生态移 民、生态环境监测与监管体制、绩效考核等配套政 策的影响。

海域专项评价结果成因分析的思路也基本与 陆域相同, 两者的区别在于海域专项评价针对的主 体功能区类型为重点开发用海区、海洋渔业保障区 和重要海洋生态功能区。海域专项评价结果成因 分析的要点在于从海域自然本底条件、涉海人类活
动以及管理政策体系三个维度,解析重点开发用海 区围填海、海洋渔业保障区渔业资源、重要海洋生 态功能区生态系统等的状态成因。

\section{6 预警等级类区成因分析}

陆域预警等级类区成因分析重点依据基础、专 项评价及成因分析结果, 采用因子分析、层次分析、 主成分分析等方法, 重点分析土地资源压力、水资 源开发利用、环境污染物浓度超标、生态系统健康 等方面的状态以及变化趋势, 识别和定量评价超载 关键因素及其作用程度,并从自然禀赋条件、经济 社会发展、资源环境管理等维度阐释不同功能区超 载成因。通过陆域超载区域与基础评价、专项评价 结果的叠加分析, 䇥选超载和临界超载类型中导致 陆域资源环境耗损状态发生变化的关键因子,采用 多因素叠加分析法, 刻画陆域水土资源组合超载、 水资源与环境组合超载等若干不同要素的组合超 载特征,并采用过程追因剖析造成陆域不同预警等 级的原因。

采用因果关系链分析等方法, 重点分析海洋资 源利用方式、规模及强度对海洋资源产生的压力, 沿海地区发展方式、规模、结构及水平对海域生态 环境的影响,并从海域自然条件、海洋和岸线资源 开发利用、陆海关系以及政策管理等维度阐释不同 海洋功能区超载成因。通过海域超载区域与基础 评价、专项评价结果的叠加分析, 篮选超载和临界 超载类型中导致海域资源环境耗损状态发生变化 的关键因子, 采用多因素叠加分析法, 刻画海域生 态环境组合超载、空间资源与环境组合超载等若干 不同要素的组合超载特征,并采用过程追因(尤其 是陆源追因)剖析造成海域不同预警等级的原因。

\section{3 应用案例}

京津冀地区包括北京、天津和河北 3 个省市, 下 辖 203 个县级行政区, 土地总面积约 22.69 万 $\mathrm{km}^{2}$ 。 根据 2016 年开展的资源环境承载能力预警评价结 果, 京津冀地区陆域和海域的资源环境承载状况都 极不乐观。主要特点一是超载范围广、面积大、程 度深; 二是城市化地区, 尤其是优化和重点开发区 域的超载问题更为突出 (陆大道, 2015; 焚杰等, 2016)。导致超载的因素涉及自然、发展和管理等 各个类别, 但关键因素的作用程度及其组合叠加状 况在基础评价结果、专项评价结果和综合预警的超 
载成因方面存在较大差异。

\section{1 陆域基础和专项评价结果成因的关键因素及作 用程度}

京津冀地区陆域评价结果成因分析显示, 土地 压力大和压力中等的地区主要分布在京津、石家 庄、保定、廊坊等建成区以及重点生态功能区中的 张北地区, 前者人口数量多、产业高度集聚是主要 原因, 后者是自然生态系统脆弱及土地沙化所致。 水资源大面积超载的原因一是水资源缺乏(李九一 等, 2012), 加深了供需矛盾且削弱了环境的自我修 复能力; 二是与经济、人口的快速增长有关。大气 环境的首要污染物是 PM2.5 和 PM10, 大面积超标 是排放量过大与不利于颗粒物扩散的气象条件叠 加的结果(杨洪斌等, 2012), 尤其在冬季采暖季, 易 形成大范围雾䨪天气; 水环境污染物主要是溶解 氧, 大范围超标的自然原因一是与海河流域水资源 缺乏有关(朱瑶等, 2013), 二是和近半个世纪以来降 雨量和河流径流量明显减少, 也造成地表径流污染 物自净能力降低有关。生态健康度低的地区除生 态脆弱地区外, 还有在唐山和河北南部地市, 不仅 有城市化地区, 还有农业地区、矿区, 显然强度较大 的工农业生产活动是导致其生态健康度低的主导 因素。牧业地区评价结果超载和临界超载的 3 个县 均和草原生态退化及过牧有关, 农业地区评价结果 恶化的区域主要分布在太行山山前平原和黑龙岗 流域地区, 既有土壤肥力较低的原因, 又有作物种 植强度较大, 有机质和氮肥投人不足的原因。

为能从整体上反映陆域基础评价和专项评价 结果成因的关键因素及其作用程度, 针对土地、水 资源、环境、生态等基础评价结果和城市灰䨪、农区 耕地、牧区草畜平衡、生态安全等专项评价结果, 分
别选择自然条件、资源禀赋、其他等自然类因素, 人 口、产业、其他等发展类因素和法规、政策、其他等 管理类因素,采用分层结对对比和专家判定等方 法, 研究形成了陆域基础和专项评价结果成因关键 因素作用程度分异特征表(表2)。从表 2 可以看出, 人口、产业等发展类因素是导致土地压力大、水资 源超载、环境污染严重和生态健康度低的主要成 因, 其作用程度普遍高于自然类和管理类因素。此 外, 水资源超载还与降水量偏少、水资源供给量严 重不足有密切关系; 环境污染还与气象条件、纳污 能力小等自然因素以及政策不严、执行力度低等管 理因素有较大关系; 生态健康度低的区域大都属于 自然条件差和历史上人类活动强度过大有关。

\section{2 陆域基础和专项评价结果成因的关键因素及作 用程度}

采用与陆域相同的思路和方法, 研究形成的海 域基础和专项评价结果成因关键因素作用程度分 异特征如表 3 。海域评价结果成因与陆域基本一 致,不同之处在于发展类、自然类和管理类因素的 作用程度普遍低于陆域。(1)生态退化是导致海域 评价多项指标超载的主导因子。近年来, 渤海近岸 及海域浮游和底栖生物群落退化、海洋生物量及潮 间带湿地生态质量显著下降, 渔场资源密度衰退 (关道明等, 2016), 秦皇岛市辖区近 10 年来海洋生 态灾害风险趋高。上述因素导致海洋生态承载状 态评价结果中仅有滨海新区结果为可载,其余均为 超载或临界超载;重点海洋生态功能区评价的两项 指标结果均为显著退化或退化;海洋渔业资源承载 能力评价结果全部为临界超载。(2岸线和近海海 域开发利用强度大是海洋空间资源、重点开发用海 区超载、海洋渔业资源受损的主要原因。海洋空间

表 2 陆域基础和专项评价结果成因的关键因素及作用程度

Tab.2 Key factors and impact of land system basic and specific evaluation results

\begin{tabular}{|c|c|c|c|c|c|c|c|c|c|c|}
\hline & \multirow{2}{*}{ 评价结果 } & \multicolumn{3}{|c|}{ 自然类因素 } & \multicolumn{3}{|c|}{ 发展类因素 } & \multicolumn{3}{|c|}{ 管理类因素 } \\
\hline & & 自然条件 & 资源禀赋 & 其他 & 人口 & 产业 & 其他 & 法规 & 政策 & 其他 \\
\hline \multirow{4}{*}{$\begin{array}{l}\text { 陆域 } \\
\text { 基础 } \\
\text { 评价 }\end{array}$} & 土地压力状态 & ++ & +++ & + & +++++ & ++++ & ++++ & ++ & ++ & ++ \\
\hline & 水资源超载状态 & +++ & +++++ & ++++ & +++++ & +++++ & ++++ & ++ & ++ & ++ \\
\hline & 环境污染状态 & ++++ & ++ & +++++ & +++++ & +++++ & ++++ & +++ & +++ & ++ \\
\hline & 生态健康状态 & ++++ & ++ & +++ & ++++ & ++++ & +++ & ++ & +++ & ++ \\
\hline \multirow{4}{*}{$\begin{array}{l}\text { 陆域 } \\
\text { 专项 } \\
\text { 评价 }\end{array}$} & 城市地区灰䨪状况 & ++ & +++ & ++++ & +++++ & +++++ & ++++ & ++ & ++ & ++ \\
\hline & 农业地区耕地质量 & +++ & +++ & ++ & ++++ & +++++ & +++ & ++ & ++ & ++ \\
\hline & 牧业地区草畜平衡 & ++ & +++ & +++ & +++ & +++++ & ++++ & +++ & +++ & ++ \\
\hline & 生态地区生态安全 & ++++ & ++ & +++ & ++++ & ++++ & +++ & +++ & +++ & +++ \\
\hline
\end{tabular}

注: + 是指因素对评价结果的作用程度, +++++ 大 $;++++$ 较大 $;+++$ 中等;++ 较小; $;$ 小。 
表 3 海域基础和专项评价结果成因的关键因素及作用程度

Tab.3 Key factors and impact of marine system basic and specific evaluation results

\begin{tabular}{|c|c|c|c|c|c|c|c|c|c|c|}
\hline & \multirow{2}{*}{ 评价结果 } & \multicolumn{3}{|c|}{ 自然类因素 } & \multicolumn{3}{|c|}{ 发展类因素 } & \multicolumn{3}{|c|}{ 管理类因素 } \\
\hline & & 自然条件 & 资源禀赋 & 其他 & 人口 & 产业 & 其他 & 法规 & 政策 & 其他 \\
\hline \multirow{4}{*}{$\begin{array}{l}\text { 海域 } \\
\text { 基础 } \\
\text { 评价 }\end{array}$} & 海洋空间资源状态 & + & + & + & ++ & ++++ & ++ & + & + & + \\
\hline & 海洋渔业资源状态 & + & +++ & + & ++ & ++++ & ++ & + & + & + \\
\hline & 海洋生态环境状态 & ++ & + & + & ++ & ++++ & +++ & + & + & + \\
\hline & 海岛资源环境状态 & ++ & +++ & + & + & +++ & + & + & + & + \\
\hline \multirow{3}{*}{$\begin{array}{l}\text { 海域 } \\
\text { 专项 } \\
\text { 评价 }\end{array}$} & 重点用海区围填海 & + & + & + & +++ & +++++ & ++ & ++ & ++ & ++ \\
\hline & 渔业区渔业资源 & + & ++++ & + & ++ & +++++ & ++ & ++ & ++ & ++ \\
\hline & 生态区生态系统 & ++ & ++ & + & + & +++ & + & ++ & ++ & ++ \\
\hline
\end{tabular}

注:+ 是指因素对评价结果的作用程度,+++++大;++++较大;+++ 中等;++较小;+小。

资源超载的主要原因与岸线及近海海域开发强度 较高有关, 昌黎县、曹妃甸区和滨海新区海岸线开 发强度指数都在 1.35 以上; 曹妃甸区、滨海新区和 黄骅市海域开发强度指数分别为 $0.588 、 0.489$ 和 0.372 , 导致其岸线开发强度和海域开发强度评价结 果均为较高。曹妃甸区实际监测的海岸线中, 工业 城镇岸线和港口岸线比重高达 $98 \%$, 现有海岸线多 为围海晒盐、围海养殖、填海造地等海洋开发利用 形成的人工海岸线; 同时该区围填海造地面积接近 2 万 $\mathrm{hm}^{2}$, 当前开发强度已处于超载状态。昌黎县毗 邻海岸线 $53.57 \mathrm{~km}^{2}$, 用于围塘利用的堤坝海岸线长 度占全县海岸线总长度 $71.0 \%$, 大量海洋保护区自 然海岸线被围塘养殖开发利用。近海海域的开发 一是表现在高密度养殖, 引起沿岸潮间带生态系统 压力增大、滩涂湿地生境改变, 导致海洋渔业资源 承载能力全部处于临界超载状态, 抚宁县、昌黎县 和滨海新区海洋渔业资源保障能力为受损或严重 受损; 二是表现在对无居民海岛的强度开发。

\section{3 综合预警的超载成因分析}

根据京津冀地区资源环境超载的特征分析, 最 主要的原因是经济社会快速发展引起的人类活动 强度大, 严重超过了资源环境禀赋的供给水平, 这 里面既有经济社会发展的原因, 如人口、GDP 及产 业结构状况; 又有自然环境恶化、禀赋供给水平趋 低的自身原因; 同时也有目前的资源环境管理机制 与政策也未及时适应资源环境恶化态势的原因; 多 数地区是 3 类因素叠加形成的超载。

(1) 人口、产业过度集聚是造成京津冀资源环 境整体超载的首要原因。在水资源短缺、大气环境 条件不利的背景下, 京津冀地区却用全国 $2 \%$ 的土 地面积、集中了 $8 \%$ 的人口和 $10 \%$ 的 GDP。2005 年
以来, 京津冀新增建设用地呈加快趋势, 年均增长 幅度达 $3 \%$; 土地开发强度已达 $13.5 \%$, 其中北京平 原地区开发强度已超过 50\%。城镇和产业园区用 地过度投放，“推大饼”式外延扩展，对资源能源粗 放过度开发, 大量耕地和生态空间被占用。人口和 产业高度集聚导致 83\%的城市化地区污染物排放 呈严重或重度状态, 陆源污染物排放又引起海域环 境超载。对水土资源的巨大压力主要体现为水资 源超载或临界超载的县域占 $71.9 \%$, 其中, 地下水超 载或临界超载的县域占 $79.7 \%$ 。

(2) 低端产业、能源消费结构以及污水处理设 施建设滞后进一步加剧了资源环境超载状态。京 津冀地区人才、资本、技术、产权等创新要素跨省市 流动和开放程度较低, 京津产业过度集中, 河北产 业过度分散,沿海产业布局同构化问题突出。河北 的低端产业比重较大, 粗钢、成品钢和生铁的产量 占全国总产量的 $20 \%$ 以上,焦炭产量占全国的 13\%, 资源利用效率较低。京津冀能源消费量大, 人均能耗和人均电耗分别比全国平均水平高 $29 \%$ 和 $13 \%$; 境内资源相对贵乏, $75 \%$ 通过外部输人; 能 源区域性和结构性矛盾显著, 且以煤炭为主的能源 消费结构是其大气污染物排放量大的主要原因之 一。城市郊区、县城、乡镇污水处理率偏低, 仍然有 部分生活废水未经处理直排周边自然水体, 是导致 水环境污染物超标和黑臭水体产生的重要原因。

(3) 水资源严重短缺, 是造成京津冀地区资源 环境超载的天然短板。2015 年, 京津冀地区人均水 资源量约 $233 \mathrm{~m}^{3}$, 不足全国平均水平的 $1 / 9$, 其中北 京人均水资源量只有全国平均水平的 $1 / 20$,生态用 水严重短缺, 仅占区域水资源消耗量的 $11 \%$ 。地下 水严重超采, 京津冀年均超采量达 67.6 亿 $\mathrm{m}^{3}$, 占全 
国的 $1 / 3$, 水资源总量开发利用程度达 $109 \%$,地面 沉降漏斗区面积超过 5 万 $\mathrm{km}^{2}$ 。水资源缺乏一方面 加深了资源供需的矛盾, 另一方面也增加了生态环 境的脆弱程度, 削弱了生态环境的自我修复能力。 高强度的人类活动和低供给的水资源叠加, 进一步 强化了资源环境超载的状态。地表水资源供给严 重不足, 导致京津和河北南部地区地下水全面 超载。

(4) 气象、地形条件及气候变化也是造成资源 环境超载的重要原因。京津冀大部分地区海拔较 低, 西部和北部燕山、太行山山脉环绕, 特殊的地形 条件, 导致平原区域 $40 \%$ 的时间处于静风状态, 季 节性气象条件不利于空气中细颗粒物的扩散, 尤其 在冬季采暖季。2014 年北京、天津、石家庄 PM2.5 重度和严重超标天数中, 分布在冬季(从 11 月到翌 年 2 月)的天数分别占 $44 \% 、 56 \% 、 57 \%, 2015$ 年分别 达 $71 \% 、 88 \% 、 90 \%$ 。受气候变化影响, 近半个世纪 以来, 中国中东部大部分地区降水日数逐年减少, 使得雨水对大气中污染物的冲刷作用减弱, 污染物 颗粒能够更长久地在空气中留存, 也加剧了雾䨪的 程度和频率。京津冀生态质量不高, 气候变化加速 了其质量退化, 中度及以上的退化草原占 $50 \%$ 以 上, 水土流失面积占土地面积的 $23 \%$, 重要湿地白 洋淀、衡水湖面积萎缩。陆域过程评价结果为加剧 的县域中, $50 \%$ 以上呈现生态低质量变化趋势。

(5) 内海净化能力差和海域生态退化、海岸开 发强度大综合导致海域生态环境超载。渤海是我 国唯一内海, 海水同外海交换能力差、自然净化能 力弱。渤海近岸海域浮游和底栖生物群落普遍退 化, 海洋生态系统底端的结构和功能变化导致整个 生态系统退化的风险大增。㴒南县、丰南区、黄华 市芦苇生境的生态质量状况均显著退化, 芦苇湿地 基本消失。昌黎海区文昌鱼栖息密度和生物量总 体呈明显下降趋势, 导致其重要海洋生态功能区的 评估结果为显著退化。秦皇岛市辖区近 10 年来海 洋生态灾害风险变化趋高, 自 2009 年以来连续发生 大面积褐潮灾害, 局部海域生态灾害多灾种并发已 对海洋生态安全产生了较大风险。2014年以来局 部海域绿潮规模越来越大, 对区域内个别海水浴场 产生严重影响。2015 年, 秦皇岛地区发现 9 起因食 用海虹导致的人体中毒事件, 表明该海域生态灾害 多灾种并发已经对海洋生态安全和人体健康产生 较大风险。上述原因导致重点海洋生态功能区评
价的两项指标结果均为显著退化或退化, 海洋渔业 资源承载能力评价结果全部为临界超载; 抚宁县、 昌黎县和滨海新区海洋渔业资源保障区评价结果 为受损或严重受损。

（6）资源环境管理政策尚不具备有效遏制和解 决资源环境超载的能力。京津冀地区整体资源、生 态与环境保障能力不足, 环境退化趋势加强了这种 不足,现行的环境经济政策体系、环境产权制度建 设还不能适应资源环境超载的发展态势, 不利于从 根本上遏制资源环境超载的状态。目前全国还没 有真正建立起完善的排污权交易市场机制，碳排放 权交易才也刚开始起步,由于缺乏交易的相关法律 制度和规定, 实践中还存在诸多问题。京津冀三省 市尚未形成相互衔接、分工合作的产业协作体系, 区域产业布局和产业转移政策未能站在京津冀一 体化层面上进行统筹,一些以煤炭消耗为主的高能 耗、重污染产业向农村转移,使得这些城市煤烟型 污染向农村扩散,加重了大气环境超载。交通、能 源、信息、水利等基础设施区域间协同不足,资源环 境安全保障监测网络建设布点不足, 导致对资源环 境超载状态预警不力。

\section{4 结论与建议}

本文建立了超载成因分析的总体框架, 阐释了 关键因素识别和成因分析的基本方法, 总结了陆域/ 海域基础和专项评价结果以及综合预警等级类区 成因分析的要点,通过对京津冀地区的应用案例剖 析, 表明既有的超载成因分析框架、方法及要点是 可行的,可供各省、市、自治区开展资源环境承载能 力监测预警借鉴。同时,也弥补了资源环境承载能 力监测预警研究方面存在的超载成因分析方法体 系缺失和影响因素层序不清等不足。

实证案例分析结果显示, 导致京津冀地区资源 环境超载的因素涉及自然、发展和管理各个类别, 但关键因素的作用程度及其组合叠加状况在基础 评价结果、专项评价结果和综合预警超载成因方面 存在较大差异。水资源严重短缺、地形和气象等自 然条件是导致超载的基础原因, 人口和产业过度集 聚以及低端产业、能源消费结构等发展类因素是超 载的首要原因; 内海净化能力差和海域生态退化、 海岸开发强度大综合导致了海域生态环境超载; 现 行的资源环境管理政策尚不具备有效遏制和解决 
资源环境超载的能力。

超载成因分析是资源环境承载能力监测预警 技术方法的重要组成部分, 但其研究内容涉及的范 围和因素较监测预警更为宽泛和复杂, 要求研究工 作的开展既要有更宽泛的视野, 又要与监测预警紧 密结合。同时超载成因分析也是制定超载区域限 制性政策的依据,在综合预警与政策制定之间具有 承前启后的作用, 因此, 研究工作与综合预警和政 策预研密不可分, 需要与前后两个方面的研究人员 开展深度合作。

\section{参考文献(references)}

党丽娟, 徐勇. 2015. 水资源承载力研究进展及启示 [J]. 水土 保持研究, 22(3): 341-348. [Dang L J, Xu Y. 2015. Review of research progress in carrying capacity of water resources [J]. Research of Soil and Water Conservation, 22(3): 341348.]

㚞杰. 2015. 中国主体功能区划方案[J]. 地理学报, 70(2): 186201. [Fan J. 2015. Draft of major function oriented zoning of China[J]. Acta Geographica Sinica, 70(2): 186-201.]

㚞杰, 王亚飞, 汤青, 等. 2015. 全国资源环境承载能力监测 预警(2014版)学术思路与总体技术流程[J]. 地理科学, 35 (1): 1-10. [Fan J, Wang Y F, Tang Q, et al. 2015. Academic thought and technical progress of monitoring and earlywarning of the national resources and environment carrying capacity (V 2014) [J]. Scientia Geographica Sinica, 35 (1): 1-10.]

㚞杰, 周㑆, 陈东. 2016. 环渤海一京津冀一首都(圈)空间格 局的合理组织[J]. 中国科学院院刊, 31(1): 70-79. [Fan J, Zhou K, Chen D. 2016. Reasonable organization of spatial framework for Bohai Rim-Beijing-Tianjin-Hebei-Capital (Circle) [J]. Bulletin of Chinese Academy of Sciences, 31 (1): 70-79.]

关道明, 张志锋, 杨正先, 等. 2016. 海洋资源环境承载能力 理论与测度方法的探索 [J]. 中国科学院院刊, 31(10): 1241-1247. [Guan D M, Zhang Z F, Yang Z X, et al. 2016. Research on measuring strategy of carrying capacity of marine resources and environment[J]. Bulletin of Chinese Academy of Sciences, 31(10): 1241-1247.]

国家发展和改革委员会. 2016. 资源环境承载能力监测预警 技术方法(发改规划[2016]2043 号)[R]. [National Development and Reform Commission. 2016. Monitoring and early- warning of resources and environment carrying capacity (development and reform plan[2016] No. 2043)[R].] 李九一, 李丽娟. 2012. 中国水资源对区域社会经济发展的 支撑能力 [J]. 地理学报, 67(3): 410-419. [Li J Y, Li L J. 2012. Water resources supporting capacity to regional so- cio-economic development of China[J]. Acta Geographica Sinica, 67(3): 410-419.]

陆大道. 2015. 京津冀城市群功能定位及协同发展 $[\mathrm{J}]$. 地理 科学进展, 34(3): 265-270. [Lu D D. 2015. Function orientation and coordinating development of subregions within the Jing-Jin-Ji Urban Agglomeration[J]. Progress in Geography, 34(3): 265-270.]

汤青, 徐勇, 董晓辉, 等. 2015. 芦山地震灾后重建地区土地 资源安全评价 [J]. 地理学报, 70(4): 650-663. [Tang Q, Xu Y, Dong X H, et al. 2015. Appraisal of land resources security in the post- earthquake reconstruction area of Lushan earthquake[J]. Acta Geographica Sinica, 70(4): 650-663.]

王传胜, 朱珊珊, 㚞杰, 等. 2012. 主体功能区规划监管与评 估的指标及其数据需求 $[\mathrm{J}]$. 地理科学进展, 31(12): 16781684. [Wang C S, Zhu S S, Fan J, et al. 2012. Key indicators and their data requirements for supervision and evaluation of MFOZ planning[J]. Progress in Geography, 31(12): 1678-1684.]

吴传钧, 郭焕成. 1994. 中国土地利用[M]. 北京: 科学出版 社. [Wu C J, Guo H C. 1994. Zhongguo tudi liyong[M]. Beijing, China: Science Press.]

徐勇, 刘艳华, 汤青. 2009. 国家主体功能区划与黄土高原生 态恢复 [J]. 水土保持研究, 16(6): 1-5. [Xu Y, Liu Y H, Tang Q. 2009. National major function oriented zoning and ecological environment restoration of the loess plateau [J]. Research of Soil and Water Conservation, 16(6): 1-5.] 徐勇, 张雪飞, 李丽娟, 等. 2016. 我国资源环境承载约束地 域分异及类型划分 [J]. 中国科学院院刊, 31(1): 34-43. [Xu Y, Zhang X F, Li L J, et al. 2016. Regional differentiation and classification for constraints of national resources and environment carrying $[\mathrm{J}]$. Bulletin of Chinese Academy of Sciences, 31(1): 34-43.]

杨洪斌, 邹旭东, 汪宏宇, 等. 2012. 大气环境中 PM2.5 的研究 进展与展望 $[\mathrm{J}]$. 气象与环境学报, 28(3): 77-82. [Yang H B, Zou X D, Wang H Y, et al. 2012. Study progress on PM2.5 in atmospheric environment[J]. Journal of Meteorology and Environment, 28(3): 77-82.]

中共中央办公厅. 2014. 中央有关部门贯彻落实党的十八届 三中全会<决定>重要举措分工方案(中办 [2014]8 号)[R]. [General Office of the CPC Central Committee. 2014. Implementing the important work division plan of the third plenary session of the 18th CPC central committee (general office of the CPC central committee[2014]No. 8)[R].]

周㑆, 栎杰. 2016. 中国环境污染源的区域差异及其社会经 济影响因素: 基于 339 个地级行政单元截面数据的实证 分析 [J]. 地理学报, 77(11): 1911-1925. [Zhou K, Fan J. 2016. Regional disparity of environmental pollution 
source and its socio-economic influencing factors: Based on the cross-section data of 339 cities at prefecture level or above in China[J]. Acta Geographica Sinica, 77(11): 1911-1925.]

朱瑶, 梁志伟, 李伟, 等. 2013. 流域水环境污染模型及其应 用研究综述 [J]. 应用生态学报, 24(10): 3012-3018. [Zhu Y, Liang Z W, Li W, et al. 2013. Watershed water environment pollution models and their applications: A review[J]. Chinese Journal of Applied Ecology, 24(10): 3012-3018.]

Ehrlich P R, Holdren J P. 1971. Impact of population growth [J]. Science, 171: 1212-1217.
Fan J, Sun W, Zhou K, et al. 2012. Major function oriented zone: New method of spatial regulation for reshaping regional development pattern in China[J]. Chinese Geographical Science, 22(2): 196-209.

House P W. 1974. The carrying capacity of a region: A planning model[J]. Omega, 2(5): 667-676.

Price D. 1999. Carrying capacity reconsidered[J]. Population and Environment, 21(1): 5-26.

Xu Y, Tang Q, Fan J, et al. 2011. Assessing construction land potential and its spatial pattern in China[J]. Landscape and Urban Planning, 103(2): 207-216.

\title{
Method and application of cause analysis for early-warning of resource and environmental system overloading
}

\author{
XU Yong ${ }^{1}$, ZHANG Xuefei ${ }^{1,2}$, ZHOU Kan ${ }^{1}$, WANG Chuansheng ${ }^{1}$, XU Xiaoren ${ }^{1,2}$ \\ (1. Institute of Geographic Sciences and Natural Resources Research, CAS, Beijing 100101, China; \\ 2. University of Chinese Academy of Sciences, Beijing 100049, China)
}

\begin{abstract}
Establishing the monitoring and early-warning mechanism for resource and environmental system overloading and implementing restrictive policies in overloaded areas is a vital task faced by the central government in China in the process of comprehensive and deepening reforms. Cause analysis of overloading is the most important technology of the monitoring and early-warning system of resource and environmental carrying capacity. It is also the basis of formulating regional restrictive policies. This research first sets up an overall framework for the cause analysis of overloading, then describes the key factors and the methods for analysis. Based on this framework, the study conducts basic evaluations, specific evaluations, and comprehensive analysis of overloading for the land and marine systems, and summarizes some important findings. Finally, it conducts an empirical study on the resource and environmental system of the Beijing-TianjinHebei region. The results show that the causes of resource and environmental system overloading in the BeijingTianjin-Hebei region can be divided into natural, developmental, and management factors. The primary causes of overloading are developmental factors such as excessive concentration of population and industries, low-end industries, and energy consumption structure. Water resources shortage and the landform and climate are the main reasons for the overloading. The overloading of the marine environment is due to the poor purification ability of the inland sea, the ecological degradation of the sea area, and the intensity of coastal development. In addition, the dominant factors and their interactions varied in different regions. The difference is not only seen in the basic evaluations, but also in the specific evaluations and comprehensive analysis of overloading. Unfortunately, the existing resource and environmental management policies cannot effectively contain and solve the overloading problem of the resource and environmental system, and more effective measures need to be explored. The framework, methods, and cause analysis of overloading developed in this study can be used by the national and local governments for the monitoring and early- warning of the resource and environmental carrying capacity overloading.
\end{abstract}

Key words: resource and environmental carrying capacity; causes for overloading; factor interactional analysis; Beijing-Tianjin-Hebei region 